\title{
APRESENTAÇÃO
}

\section{POR UMA PEDAGOGIA MACUNAÍMICA: INFÂNCIAS, ESTUDOS DECOLONIAIS E RESISTÊNCIAS PLURAIS NA CONTEMPORANEIDADE}

\author{
https://orcid.org/0000-0002-1407-783X Adriana Alves da Silva ${ }^{\mathrm{A}}$ \\ https://orcid.org/0000-0002-9856-5098 Maria Tereza Goudard Tavares ${ }^{B}$ \\ ${ }^{\text {A }}$ Universidade do Estado de Santa Catarina (UDESC), Florianópolis, SC, Brasil \\ ${ }^{\text {B } U n i v e r s i d a d e ~ d o ~ E s t a d o ~ d o ~ R i o ~ d e ~ J a n e i r o, ~ F a c u l d a d e ~ d e ~ F o r m a c ̧ a ̃ o ~ d e ~ P r o f e s s o r e s ~(U e r j, ~ F F P), ~ S a ̃ o ~ G o n c ̧ a l o, ~ R J, ~ B r a s i l ~}$
}

O mundo marcha para o primitivismo. Hoje, porém, os sardinhas evolucionam bem rapidinho. São tubarões. Comamos, pois, os tubarões. Patrícia Galvão, Pagu, 1929.

Inspirado na irreverência de Pagu, resistindo antropofagicamente em tempos sombrios com águas turvas pela barbárie genocida à brasileira, o presente dossiê se propõe a homenagear de forma direta os 25 anos do Grupo de Estudos e Pesquisas em Educação e Diferenciação Sociocultural (GEPEDISC), linha Culturas Infantis, sediado na Faculdade de Educação da UNICAMP/SP e coordenado pela professora doutora Ana Lúcia Goulart de Faria. E, de forma indireta, homenageia o centenário da Semana de Arte Moderna (1922-2022), compreendendo a importância e as ressonâncias que o Movimento Modernista - sobretudo a obra do poetaescritor, educador e pensador Mário de Andrade - teve e tem nos percursos de trabalho e pesquisa do GEPEDISC- Culturas Infantis.

A aposta deste dossiê ancora-se, também, na complexidade e na capacidade inventiva e aglutinadora da "Pedagogia Macunaímica", proposta por Ana Lúcia Goulart de Faria, a partir de seus estudos de doutoramento (1994) sobre os parques infantis da cidade de São Paulo, projeto idealizado por Mário de Andrade, no período de 1935-1938.

Dentre as principais contribuições do GEPEDISC - Culturas Infantis à Educação das infâncias brasileiras, vislumbramos a Pedagogia Macunaímica, pensada por Ana Lúcia Goulart de Faria como uma pedagogia brincante, fundamentada na arte e na brincadeira, nas culturas infantis, sintonizada com as diferentes infâncias e crianças brasileiras que, vivendo em um país continental como o Brasil, produzem suas (re)existências em territórios constituídos por uma 
formação multiétnica e uma enorme diversidade cultural. Uma Pedagogia Macunaímica que, em sua força política, epistêmica e cultural, nos inspira a celebrar e perscrutar os possíveis impactos e influências da Semana de Arte Moderna, realizada em São Paulo, no período de 13 a 18 de fevereiro de 1922, na educação brasileira, especialmente na educação das infâncias das classes populares, problematizando - de forma original e inédita - os impactos objetivos e subjetivos de uma herança colonial eurocêntrica, adotada hegemonicamente nas pedagogias direcionadas às crianças brasileiras.

Nessa perspectiva, o centenário da Semana de Arte Moderna (1922-2022) surgiu como uma oportunidade ímpar, um espaço-tempo fundamental para aprofundarmos a questão de uma Pedagogia Macunaímica, tão cara à professora doutora Ana Lúcia Goulart de Faria, pesquisadora criancista, criançóloga, feminista, anticapitalista e paulistana desvairada, e a todxs pesquisadorxs do GEPEDISC/Culturas Infantis que, ao comemorar 25 anos de estudos e pesquisas na FE/Unicamp, nos presenteiam com um percurso de trabalho dos mais profícuos, originais e provocativos no campo da Educação Infantil brasileira e Latino-americana, legandonos uma obra plural, instigante e militante.

Uma Pedagogia Macunaímica que, ao assumir uma perspectiva "antropofágica" (ANDRADE, 1928), nos provoca ao desafio de pensar uma educação infantil que não aparta ciência e arte, educar e cuidar, pensar e fazer, criar e inventar, pedagogia e política, procurando pensar/problematizar, sobretudo com Mário de Andrade, Oswald de Andrade, Tarsila do Amaral, Anita Malfatti, Patrícia Galvão, Di Cavalcanti, Villa-Lobos, Câmara Cascudo, Manuel Bandeira, Raul Bopp, Cecília Meirelles, dentre outrxs, o caráter inacabado da experiência da Semana de Arte Moderna, perscrutando e reconstruindo as suas possibilidades utópicas e germinativas. Em tempos tão trágicos, atravessados por uma pandemia tanto política quanto epidemiológica, que há mais de 2 anos não cessa de nos fragilizar e aterrorizar, explicitando diante dos nossos olhos um amontoado de escombros (BENJAMIN, 2013), é urgente nos abrirmos às possibilidades que as energias utópicas do passado podem nos oferecer.

Nessa perspectiva, o presente dossiê é uma tentativa de trazermos à discussão um pensamento pedagógico alternativo de alternativas, risível, brincante, decolonial, antropofágico, impertinente e "Pau-brasil". Uma pedagogia que se afirma como:

\footnotetext{
Contra todas as catequeses. E contra a mãe dos Gracos. (...)

Contra todos os importadores de consciência enlatada. A existência palpável da vida.

E a mentalidade pré-lógica para o Sr. Levy Bruhl estudar. (...)

Contra o mundo reversível e as ideias objetivadas. Cadaverizadas. (...)
} 
Contra as sublimações antagônicas. Trazidas nas caravelas.

Contra a memória fonte dos costumes. A experiência pessoal renovada. (ANDRADE, 2011, p. 67)

Nesses tempos sombrios, a experiência pessoal renovada pode ser reverberada como resistência, aqui entendida não como pura reação aos poderes do fascismo e da necropolítica (MBEMBE, 2016) que vicejam no país, mas, justamente, como uma outra forma de existir. Isto é, pensar a resistência enquanto afirmação de processos inéditos de vida, nos quais a escrita, a arte, a imagem, a infância, a política, a poética, a Semana de Arte Moderna e a Pedagogia Macunaímica expressam potências que anunciam, em meio a escombros, outras formas de vida, de relações, de criações, de pensar e praticar a educação de crianças pequenas no país. Tal como nos convida a pensar Ana Lúcia Goulart de Faria, na entrevista "Dos parques Infantis à Educação Brasileira: O que a Semana de 22 tem a ver com isso?", no presente dossiê:

(...) Quero deixar registrado que a pedagogia macunaímica,

se a gente quiser festejar como a Semana de 1922, ela vem dos estudos

que eu faço dos parques Infantis, contato com a natureza, relação horizontal

com as crianças, e a forma não escolar e não da psicologia de falar da Educação Infantil.

Embaladas pelas palavras de Ana Lúcia, em sua entrevista, e pelos diálogos com os artigos/seções que compõem o presente dossiê, gostaríamos de enfatizar que o processo de construção de pedagogias descolonizadoras impõe-se como um desafio à complexidade de nosso legado colonial, racista, patriarcal adultocêntrico, sendo a Pedagogia Macunaímica (...) "uma pedagogia da escuta, a pedagogia das relações e a pedagogia das diferenças, que foi o que eu aprendi na Itália (...) Eu trago isso e a experiência que eu vou chamar, no Brasil, de Pedagogia Macunaímica".

Assim, o presente dossiê é composto por dez artigos inéditos, um ensaio poéticoliterário- antropofágico, além da entrevista da coordenadora do GEPEDISC/Culturas Infantis Ana Lúcia Goulart de Faria e duas resenhas pensadas em diálogo com o "espírito" do Dossiê. A primeira resenha é intitulada "Cartas a uma Negra: Um encontro epistolar entre Françoise Ega e Carolina de Jesus", do livro Cartas a uma Negra Ega, escrito por Françoise Ega e recém publicado no Brasil; e a segunda, "Biografia de Mário de Andrade: um tupi tangendo um alaúde", do livro Em busca da alma brasileira: biografia de Mário de Andrade, escrita por Jason Tércio. Reiteramos que as resenhas buscam apresentar para leitorxs obras que nos convidam a leituras sensíveis e experimentações estético-literárias que também expressam 
possibilidades de produzir resistências e festejar a vida, em meio às comemorações do centenário da Semana de 22.

Em síntese, todos os artigos, a entrevista e as resenhas que integram o dossiê temático "Por uma Pedagogia Macunaímica: Infâncias, Estudos Decoloniais e Resistências Plurais na Contemporaneidade" buscam problematizar, aprofundar e provocar o pensamento dxs leitorxs, produzindo interfaces e ressonâncias entre a temática do dossiê e o caráter polifônico, irreverente, rebelde, decolonial e transgressor da Semana de Arte Moderna (13 a 18/02/1922), cujo centenário buscamos - com espírito de resistência e alegria - homenagear.

Mobilizadas pelo desejo de diálogo e interlocuções, abrimos o dossiê com o artigo PEDAGOGIA MACUNAÍMICA: INSPIRAÇÕES MODERNISTAS PARA A PENSAR A ESCOLA E O BRASIL CONTEMPORÂNEO, que, escrito sob a forma ensaística, convidanos a pensar o tempo presente e a atual crise pandêmica do coronavírus, retomando o espírito irreverente e transgressor do Movimento Modernista no Brasil, sobretudo a obra seminal de Mário de Andrade, Macunaíma, o herói sem nenhum caráter (1928), compreendida como uma rapsódia sobre a formação do Brasil, na qual vários elementos do caráter nacional se hibridizam, possibilitando uma leitura pautada no Giro decolonial e não eurocêntrica do comportamento do povo brasileiro. No artigo, somos convidados/as/xs a pensar a escola/educação brasileira a partir de uma pedagogia macunaímica, que, sustentada em paradigmas outros, aposta numa relação Educação/Sociedade pautada em diálogo com o campo cultural e o pensamento social brasileiro contemporâneo, pensando-nos - o Brasil e o povo brasileiro - numa perspectiva intercultural, decolonial e antropofágica.

O segundo artigo, MÁRIO DE ANDRADE: TURISTA APRENDIZ EM TERRA ARRASADA, DA AMAZÔNIA A SÃO PAULO, ATÉ DIZER CHEGA, também escrito sob a forma ensaística, objetiva apresentar reflexões sobre a densa e tensa paisagem de determinadas regiões brasileiras a partir dos diários de viagens de Mário de Andrade ao norte e nordeste brasileiro, ao Brasil Profundo nos anos de 1927, 28 e 29, principalmente à região Amazônica, em 1927. Para as autoras do artigo, na escrita etnográfica e envolvente do "Turista Aprendiz", reverberam questões que urgem ser problematizadas: o que é possível pensar/aprender das viagens Andralinas quase um século depois e 100 anos da Semana de Arte Moderna?

O terceiro artigo, A HERANÇA MARIOANDRADIANA: FONTE DE INSPIRAÇÃO PARA PESQUISAS DECOLONIAIS, apresenta o entrelaçamentos entre trabalhos de pesquisas realizados na graduação, mestrado e doutorado em Educação, focalizando relações entre educação e cultura na Educação Infantil, principalmente, a partir do diálogo com Ana 
Lúcia Goulart de Faria (2002,) em sua obra sobre os Parques Infantis (1935-1938) pensados e implementados por Mário de Andrade na capital paulista, no período em que o mesmo foi diretor do Departamento de Cultura de São Paulo. O artigo aprofunda o diálogo com obras de Mário de Andrade, apontando inúmeras intersecções entre os campos da educação e cultura, aprofundando a questão da Cultura Popular e das Artes numa pedagogia decolonial, afirmando o papel da linguagem corporal e das danças no legado Marioandradiano na educação das infâncias brasileiras.

O quarto artigo, O INDIANISMO E O LENDÁRIO EM IRACEMA DE JOSÉ DE ALENCAR E MACUNAÍMA DE MÁRIO DE ANDRADE - a partir do cotejamento de duas obras literárias, Iracema de José de Alencar e Macunaíma de Mário de Andrade, apresenta aproximações e distanciamentos entre os dois autores que, apesar de trabalharem a figura do índio com herói, o representam de forma radicalmente diferentes. $\mathrm{O}$ artigo com base na literatura comparada enfatiza o papel político da relação entre educação e Literaturas, aproveitando para reencontrar-se com a semana de Arte Moderna, e o espírito modernista de Mário de Andrade, no ensaio de uma escrita manifesto, saudando a pluralidade das literaturas brasileiras.

No quinto artigo, "VIRANDO DE PONTA A CABEÇA": INSPIRAÇÕES DECOLONIAIS PARA UMA PEDAGOGIA COM AS INFÂNCIAS coloca em discussão movimentos teóricos, políticos e epistemológicos que interrogam pedagogias sustentadas por lógicas adultocêntricas de negação, principalmente das infâncias de crianças das classes populares. O texto nos convida a incorporar, de forma crítica e antropofágica, lutas e rebeldias que crianças produzem em seus percursos de emancipação, sobretudo como partícipes de movimentos sociais, questionando e criando pedagogias decoloniais em suas ações rebeldes e anticapitalistas.

O sexto artigo, "JONAS E O CIRCO SEM LONA": ENTRE O CIRCO E A ESCOLA, OLHAR UMA INFÂNCIA, escrito em um estilo político e poético, busca-se o encontro e o diálogo com o filme "Jonas e o circo sem lona" (2015), convidando-nos a uma aprendizagem do olhar a infância e a escola procurando não folclorizar ou exotificar a vida e os saberes dos sujeitos populares, principalmente do povo que produz a arte da vida no nordeste brasileiro. $\mathrm{O}$ artigo busca poeticamente transver a infância, colocando em diálogo cinema, infância e arte circense.

O sétimo artigo, EDUCAÇÃO INFANTIL E AFETO: TECENDO FIOS, DESATANDO NÓS, CONSTRUINDO IDEIAS, DESEMPAREDANDO A VIDA E AS 
INFÂNCIAS fundamenta-se no diálogo com autorxs que, numa perspectiva de-pós-colonial, apostam numa pedagogia antirracista, anticapitalista, brincante, indígena e quilombola. $\mathrm{O}$ artigo nos provoca apensar o papel de filosofia não-maquínica (DELEUZE, 1992), ecosófica (GUATTARI, 1990), que fundadas na força da afetividade, das diferenças e da alegria de uma educação desemparedada, possa produzir agenciamentos felizes e libertários na educação Infantil.

O oitavo artigo, PERIPÉCIAS DO SACI, FORMAÇÃO DOCENTE E AULAS ANTROPOFÁGICAS, objetiva apresentar e problematizar o mito popular brasileiro do Saci Pererê, pensando-o como um elemento cultural relevante no imaginário da formação docente, em especial no nordeste brasileiro. $\mathrm{O}$ artigo intenciona analisar as potencialidades do mito do Saci Pererê numa perspectiva decolonial, crítica e criativa, dialogando com autorxs como Mário de Andrade, Monteiro Lobato, Pierre Bourdieu, dentre outrxs, além de se basear em relatos de experiências formativas realizadas com um grupo de estudantes de mestrado, vinculadxs a dois Programas de Pós-Graduação sediados no nordeste brasileiro.

O nono artigo, denominado UM DIA DESCERÁ NUMA ESTRELA COLORIDA E BRILHANTE: MEMÓRIAS DE UMA PEDAGOGIA MACUNAÍMICA, busca trazer à tona experiências e percursos dxs autorxs quanto às suas vivências pessoais e profissionais, em diálogo com estudos pós-coloniais e com o Movimento Modernista brasileiro, sobretudo com Mário de Andrade. O artigo discorre também sobe o conceito de pedagogia macunaímica, em diálogo com Ana Lúcia Goulart de Faria, optando metodologicamente por apresentar um memorial formativo como relato de experiência da autora e do autor em seus processos e percursos no campo da educação e da Arte.

E o décimo artigo, INFÂNCIAS E A LUTA DAS MULHERES: RESISTÊNCIAS PLURAIS, FEMINISMOS E PEDAGOGIA DESCOLONIZADORAS, se apresenta como resultante de pesquisas sobre infâncias, feminismos plurais e estudos decoloniais realizados no âmbito do GEPEDISC - Culturas Infantis, fundamentando-se numa perspectiva epistemológica interseccional e considerando o nó (SAFFIOTTI, 2015) que ata capitalismo-patriarcado, enredando classes, sexismo e racismo. O artigo, entretecido por dois movimentos teóricoempíricos, coloca em diálogo diferentes formas de resistências de mulheres-mães que vivem com seus/suas/sexs filhos, filhas e filhxs na cidade de Manaus, capital do estado do Amazonas, concentradora do maior contingente de população indígena no país.

Encerrando o dossiê, o ensaio poético-literário-antropofágico "AGORA EU ERA HERÓI”: UMA RAP(SÓDIA)TERAPÊUTICO-ANTROPOFÁGICA AUDIOVISUAL DO 


\section{CARÁTER DE HERÓIS, ANTIHERÓIS, SUPER-HERÓIS, HEROÍNAS E CRIANÇAS} apresenta uma experiência-literária textual híbrida - antropofagicamente elaborada, compondo coletivamente um rap-poema cênico que busca convidar e proporcionar a leitorxs e expectadorxs experiências performativas de leitura (des)equilibristas, ditas (auto)terapêuticas, no sentido wittegensteiniano e antropofágico, no sentido do Manifesto Antropófago de Oswald de Andrade. Questiona narrativas que inventam heróis, anti-heróis, super-heróis e heroínas, sempre encenando-os/as já adultos/as - eles/elas são sempre não-crianças, com exceção, talvez, de Macunaíma, que já nasce herói, ainda que sem nenhum caráter - e que as raras memórias de seus tempos de criança só muito recentemente começam a adentrar às salas de cinema, com o propósito de desconstruir derridianamente as imagens ideológicas de heróis que essas narrativas mobilizam.

Consideramos que o presente texto encerra (produzindo dobras) de forma contundente a proposta do dossiê, enfatizando com radicalidade crítica o seu espírito poético-político de inspiração modernista, provocativa e brincante. Reiteramos que, de uma forma ou de outra, todos os artigos aqui reunidos discutiram "as Artes de Educar" no contexto social-nacionalmundial, inserindo-as na profunda crise do capitalismo global/nacional das primeiras décadas do século XXI. Conjugado à falta de políticas efetivas de controle da pandemia do Corona Vírus, e em meio a uma crise ambiental sem precedentes, ainda sofre com esgarçamentos cotidianos causados pela descrença nas formas de democracia representativa, e, principalmente, pela assunção ao poder de governos nazi-necro-fascistas, como o que temos no Brasil.

Porém, apesar desse cenário sombrio, armadilhoso e complexo, todos os artigos aqui elencados apostam "macunaimicamente" na vida e nas possibilidades de insurgências, resistências e rebeldias coletivas tão necessárias ao anúncio de outro(s) projeto(s) de sociedade/educação. Como em um coro, somamos nossas vozes de organizadoras às diferentes vozes dx autorxs do dossiê. E para concluir e convidar à leitura, trazemos a voz de Oswald de Andrade, em seu Primeiro Caderno do Alumno de Poesia, escrito em 1927, que foi considerado por Augusto de Campos (2018) como "possivelmente o mais belo livro de poesia de nosso modernismo". Com a sua escrita assumidamente otimista e transgressora, trata-se da obra de um poeta que mergulha na infância do sujeito lírico para criar uma linguagem nova para si e para o país que busca passar a limpo, entre o riso e a subversão: 


\section{POEMA DE FRAQUE}

No thermometro azul

Da cidade comovida

Faze as pazes

Com a vida

Sauda respeitosamente

As famílias

Das janellas

Um balão vivo

Se destaca

Das primeiras estrellas

Lamparina às avessas

Do santuário da terra

Faze as pazes

As Creanças brincam

(Oswald de Andrade, 1927)

E as crianças brincam... e a constelação de Ursa Maior busca macunaimicamente cuidá-las! Boa leitura!

\section{Referências}

ANDRADE. Oswald de. Primeiro Caderno do alumno de Poesia. São Paulo: Typographia da Rua Santo Antonio, n 19, 1927.

ANDRADE. Oswald de. A Utopia Antropofágica. 4. ed. São Paulo: Globo, 2011.

BENJAMIN, Walter. O Anjo da História. 2.ed. Belo Horizonte: Autêntica, 2013.

CAMPOS, Augusto de. Oswald, livro livre. In: Sobre o Primeiro Caderno do Alumno de Poesia Oswald de Andrade. 1. ed. São Paulo: Companhia das Letras, 2018.

DELEUZE, Gilles. Conversações. Tradução Peter Pál Pelbart. Rio de Janeiro: Editora 34, 1992.

GUATTARI, Félix. As Três Ecologias. São Paulo: Papirus, 1992. 
MBEMBE, AChille. Necropolítica. 6a .ed. São Paulo: N-1, 2018. SAFFIOTTI, Heleieth. Gênero, Patriarcado, Violência. São Paulo: Expressão Popular, 2015. 